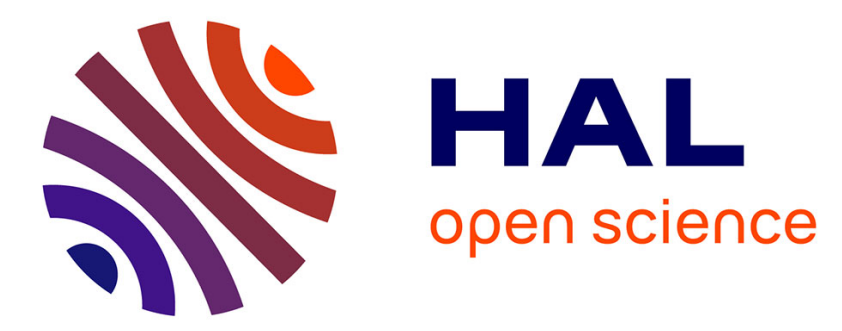

\title{
Proteomic analysis of bronchoalveolar lavage fluid in rat exposed to TiO2 nanostructured aerosol by inhalation
}

\author{
Laëtitia Chezeau, Lori Kohlstaedt, Alain Le Faou, Frédéric Cosnier, Bertrand
} Rihn, Laurent Gaté

\section{- To cite this version:}

Laëtitia Chezeau, Lori Kohlstaedt, Alain Le Faou, Frédéric Cosnier, Bertrand Rihn, et al.. Proteomic analysis of bronchoalveolar lavage fluid in rat exposed to TiO2 nanostructured aerosol by inhalation. Journal of Proteomics, 2019, 207, pp.103451. 10.1016/j.jprot.2019.103451 hal-02922927

\section{HAL Id: hal-02922927 \\ https://hal.univ-lorraine.fr/hal-02922927}

Submitted on 25 Oct 2021

HAL is a multi-disciplinary open access archive for the deposit and dissemination of scientific research documents, whether they are published or not. The documents may come from teaching and research institutions in France or abroad, or from public or private research centers.
L'archive ouverte pluridisciplinaire HAL, est destinée au dépôt et à la diffusion de documents scientifiques de niveau recherche, publiés ou non, émanant des établissements d'enseignement et de recherche français ou étrangers, des laboratoires publics ou privés.

\section{(ㄷ)(1) $\$$}

Distributed under a Creative Commons Attribution - NonCommercial| 4.0 International 


\section{Proteomic analysis of bronchoalveolar lavage fluid in rat exposed to $\mathrm{TiO}_{2}$}

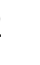

3

Laëtitia Chézeau ${ }^{1,2}$, Lori A. Kohlstaedt ${ }^{3}$, Alain Le Faou², Frédéric Cosnier ${ }^{1}$, Bertrand Rihn²,4 $^{2,}$ Laurent Gaté $^{*}$

4

$5{ }^{1}$ Institut National de Recherche et de Sécurité, Rue du Morvan, CS 60027, 54519 Vandœuvre Cedex, France

$6{ }^{2}$ EA 3452 CITHEFOR, Université de Lorraine, BP 80403, 54001 Nancy Cedex, France

$7 \quad{ }^{3}$ California Institute for Quantitative Biosciences, University of California, Berkeley CA 94720

$8 \quad{ }^{4}$ Institut Jean-Lamour, UMR 7198 CNRS, Université de Lorraine, 54011 Nancy Cedex, France

$9 \quad *$ Corresponding author: laurent.gate @inrs.fr - Tel: +33 (0)3 83508504

10

11

12

13

14

15

16

17

18

19

20

21

22

23

24

25

26

27

28

29

30 
2 The pulmonary toxicological properties of inhaled titanium dioxide were studied using

3 bronchoalveolar lavage fluid (BALF) cytology and proteomics analyses. Fischer 344 rats were

4 exposed to $10 \mathrm{mg} / \mathrm{m}^{3}$ of $\mathrm{TiO}_{2}$ nanostructured aerosol by nose-only inhalation for $6 \mathrm{~h} /$ day, 5 days/week

5 for 4 weeks. Lung samples were collected up to 180 post-exposure days. As previously described,

6 cytological analyses of BALF showed a strong inflammatory response up to 3 post-exposure days,

7 which persisted however, at a lower intensity up to 180 days. In addition, using Multidimensional

8 Protein Identification Technology (MudPIT), we identified a total of 107, 50 and 45 proteins

9 (UniprotKB identifiers) differentially expressed in exposed rats immediately, 3 and 180 days after the

10 end of exposure respectively. Increased levels of inflammatory proteins, members of proteasome, various histones, proteins involved in cytoskeleton organization, were noticed up to 3 days (short-term response). Some of these proteins were linked with Neutrophil Extracellular Trap formation (NETosis). Long-term response was also characterized by a persistent altered expression of proteins up to 180 days. Altogether, these results suggest that exposure to low toxicity low solubility nanomaterials such as $\mathrm{TiO}_{2}$ may induce long-term changes in the pulmonary protein expression pattern of which the physio-pathological consequences are unknown.

Keywords: titanium dioxide, lung inflammation, protein expression profile, short-term response, longterm response, NETosis 
1 Significance: This paper describes in rats, at the pulmonary level, the effects of inhaled

2 nanostructured aerosol of $\mathrm{TiO}_{2}$ on the secreted proteins found in the broncho-alveolar space by

3 comparing the proteomic profile in broncho-alveolar lavage fluid supernatants of control and exposed

4 animals. This work brings new insights about the early events occurring following the end of exposure

5 and suggests the formation of Neutrophil Extracellular Traps (NETosis) that could be interpret as a

6 potential early mechanism of defense against $\mathrm{TiO}_{2}$ nanoparticles. This work also describes the long

7 term effects (180 post-exposure days) of such an exposure and the change in secreted protein

8 expression in the absence of significant histopathological modifications.

9

\section{Introduction}

Due to the growing use of nanomaterials in various industrial processes, the number of workers potentially exposed is increasing even though the toxicological properties of these chemicals are still not completely known. Since nanoparticles (NPs) may get aerosolized, inhalation represents the main route of occupational exposure. Then, inhalation studies with nanomaterials in animal models appear to be the most relevant approach to assess the hazards associated with exposure to such nanostructured aerosols.

Titanium dioxide $\left(\mathrm{TiO}_{2}\right)$ is one of the most widely produced and used nanomaterials worldwide. $\mathrm{TiO}_{2}$ NPs are used in coatings, paints, self-cleaning windows, food and healthcare products, pharmaceuticals, and cosmetics including sunscreens [1].

Several studies have been published on the pulmonary toxicity of inhaled $\mathrm{TiO}_{2} \mathrm{NPs}$, mainly focusing on the inflammatory response and histopathological changes [1, 2]. However, such conventional toxicological approaches are not sufficient to identify the underlying molecular mechanisms of NP toxicity. Thus, complementary strategies such as toxicogenomics and proteomics studies are required $[3,4]$.

This is of high interest to assess the complex interplay between nanomaterials and living organisms as well as to identify any long-term adverse outcomes. Most studies involving classical 
toxicological assays and high content screening methods are limited to short post-exposure periods up to 30 days $[3,5,6]$. Only few studies have been published on longer post-exposure periods $[7,8]$.

In a previous work, we have shown using a transcriptomics approach, that following rat exposure by nose-only inhalation to a $\mathrm{TiO}_{2}$ nanostructured aerosol (NSA), 6 hours/day, 5 days/week for 4 weeks, many genes were differentially expressed in the lung of exposed animals up to 6 months after the end of animal exposure; without any significant histopathological changes except a strong inflammatory response that decreased overtime [9].

In this study, we pursue our investigation of the pulmonary toxicological properties of this $\mathrm{TiO}_{2}$ NSA by looking at the changes of protein levels in the BALF of exposed animals. For this, biological samples were analysed immediately, 3 and 180 days after the end of exposure, to investigate shortand long-term effects.

\section{Materials and methods}

\subsection{Aerosol generation and characterization}

$\mathrm{TiO}_{2} \mathrm{P} 25$ (Aeroxide $^{\circledR} \mathrm{P} 25$ Evonik $^{\circledR}$ ) was purchased from Sigma Aldrich (Saint-Quentin Fallavier, France), and was a mixed-phase nanocrystalline powder composed of $80 \%$ anatase and $20 \%$ rutile crystallites, with an average primary particle diameter of $21.5 \pm 7.2 \mathrm{~nm}$. The physical and chemical characteristics of this nanomaterial have been previously published [10]. Its main characteristics are presented in Table 1. $\mathrm{TiO}_{2} \mathrm{P} 25$ aerosol was generated at a target concentration of $10 \mathrm{mg} / \mathrm{m}^{3}$. Taking into account the interspecies differences in terms of respiratory parameters and lung deposited dose, this concentration and exposure time relate to the $8 \mathrm{~h}$ weighted average occupational exposure of a worker at $0.3 \mathrm{mg} / \mathrm{m}^{3}$ (the NIOSH recommended exposure limit for ultrafine $\mathrm{TiO}_{2}$ [11]); throughout his entire career.

The aerosol was produced using a rotating brush (RBG1000, Palas, Karlsruhe, Germany). Dry, filtered compressed air was used as the carrier gas. The aerosol was delivered simultaneously to animals maintained in nose-only restraining tubes placed in four 9-port-inhalation chambers (EMMS, Electro-Medical Measurement System, Bordon, UK). Simultaneously, control rats were exposed to 
filtered air using the same exposure setup [10]. The aerosol and filtered air were conditioned at a temperature of $22 \pm 2^{\circ} \mathrm{C}$ and a relative humidity of $55 \pm 10 \%$, in line with the OECD TG 412 guideline [12].

\subsection{Animal exposure}

Animal experiments were performed according to the European and French regulations relating to the protection of animals used for scientific purposes (European Directive 2010/63/EU). Procedures were approved by the local Ethics Committee (C2EA-66) and the French Ministry for Research and Higher Education (authorization No. 00692.01). Thirteen-week-old male Fisher F344 rats (Charles River Laboratories, France) were housed in standard environmental conditions (relative humidity: $55 \pm 10 \%$; temperature: $22 \pm 2^{\circ} \mathrm{C}$ and $12 / 12 \mathrm{~h}$ light/dark cycle). Water and a standard laboratory animal diet (A04, Safe diet) were freely available. Two weeks before exposure to $\mathrm{TiO}_{2} \mathrm{NSA}$, rats were gradually acclimatized to the restraining tubes. Animals were then exposed either to filtered air or $\mathrm{TiO}_{2} \mathrm{NSA}$ at a concentration of $10 \mathrm{mg} / \mathrm{m}^{3}$ for $6 \mathrm{~h} /$ day, 5 days/week for 4 weeks.

\subsection{Tissue sampling, bronchoalveolar lavage}

Immediately after the last 6 -hour exposure, and then 3 , and 180 post-exposure days (d0, $\mathrm{d} 3$ and d180 respectively), 5 animals per group were anesthetized with an intraperitoneal injection of pentobarbital $(60 \mathrm{mg} / \mathrm{kg})$ and exsanguinated through the abdominal aorta. The trachea was cut and the lung was removed. Bronchoalveolar lavage (BAL) was performed on the left lung by introducing icecold phosphate buffered saline (PBS) and collecting it in conical tubes. Tubes were centrifuged for 5 min at $400 \mathrm{x} g$ and $4^{\circ} \mathrm{C}$. The supernatants were taken for mass spectrometry analyses and proteome profiler experiment. The cell pellets were resuspended in ice-cold PBS for cell counting and cytospin preparation. BAL cells were counted using a Cellometer Vision (Nexcelom Bioscience, Lawrence, MA) following acridine orange/propidium iodide staining. BAL differential cell counts were performed on cytospin preparations after May-Grünwald Giemsa staining. 


\subsection{Sample preparation and MudPIT analysis of BALF}

BALF ( $n=5$ per control and exposed groups on $d 0, d 3$, and d180) was digested with trypsin. The peptides obtained were desalted and dried before loading on a column filled with $10 \mathrm{~cm}$ of Polaris $\mathrm{C} 18$ $5 \mu \mathrm{m}$ packing material (Hichrom), and $4 \mathrm{~cm}$ of Partisphere $5 \mathrm{SCX}$ (Whatman). The column was directly connected to an electrospray ionization source mounted on an LTQ linear ion trap mass spectrometer (Thermo-Fisher). Chromatographic separation of peptides was achieved at a flow rate of $300 \mathrm{~nL} / \mathrm{min}$ delivered by an Agilent 1200 HPLC equipped with a split line. Peptides were eluted using a 10-step MudPIT procedure [13]. Data were analyzed using Integrated Proteomics Pipeline (IP2) with ProLuCID program [14]. The rat database used for identifications was downloaded from EMSEMBL on May 8, 2014. A database of common contaminants was added to the rat database and the whole was concatenated with a decoy database in which the sequence for each entry in the original database was reversed to provide for the calculation of false positives [15]. Peptide identifications were set to require fully tryptic ends with a false discovery rate of 0.005 at the peptide level. Proteins were included in the dataset if there was at least one peptide match better than a false discovery rate of 0.001. The final calculated false discovery rate averaged about $1 \%$ at the protein level over all datasets used. Normalization and relative quantitation were done using the spectral counting method that provides an easy way of identifying proteins with differing abundances between complex mixtures using shotgun proteomics data. These approaches used for quantitative proteomics analyses, are based on different spectral counting metrics. In this study, we used the normalized spectral abundance factor (NSAF) and the exponentially modified protein abundance index (emPAI) [16, 17]. Differentially expressed proteins between control and exposed group, were identified at each time-point, using an ANOVA $(\mathrm{p}<0.05)$, available in the Identification Stat Compare program in IP2. Samples were statistically compared based on spectral counts. Thus, we obtained a list of differentially expressed proteins described in terms of ENSEMBL protein identifiers (ENSRNOP), at different post-exposure times. Then, UniProt Knowledge Base (UniProt KB) was used to convert ENSEMBL identifiers lists to Uniprot identifiers lists. These lists of differentially expressed proteins were analyzed using GeneCards ${ }^{\circledR}$ database and the Database for Annotation, Visualization and Integrated Discovery (DAVID) v6.7 database (https://david.ncifcrf.gov/). DAVID database was used to identify biological 
functions altered following exposure to $\mathrm{TiO}_{2}$ NSA. Proteins that share similar functions were clustered based on biological processes, cellular components and molecular functions. In this study, we mainly focused on significantly enriched Gene Ontology Biological Processes (GO BP) $\underline{\text { (significant }}$ enrichment was identified with a modified Fisher's exact test (EASE score); $\mathbf{p}<0.05$ ), or on GO BP belonging to annotation clusters with an Enrichment Score (Z score) greater than 1.3 [18].

We also examined significantly enriched KEGG (Kyoto Encyclopedia of Genes and Genomes) biological pathways ( $\mathrm{p}<0.05$ ), a collection of manually-drawn pathway maps representing knowledge on molecular interactions and reaction networks.

Protein-protein interactions (PPI) of differentially expressed proteins in BALF, were investigated on $\mathrm{d} 0, \mathrm{~d} 3$ and d180, using the Search Tool for the Retrieval of Interacting Genes/Proteins (STRING) database of physical and functional interactions v10.5 [19]. Network nodes represent proteins and edges represent protein-protein associations. Line color of network edges indicates the type of interaction evidence. Thus, known interactions are represented in light blue line (this color indicates the presence of database evidence) and purple line (experimental evidence); predicted interactions in green line (neighborhood evidence), red line (fusion evidence) and blue line (co-occurrence evidence); and others interactions in yellow line (text mining evidence), black line (co-expression evidence) and violet line (protein homology). The analysis section gives some brief statistics of the inferred network, such as the number of nodes and edges. The average node degree is a number of interactions (at the score threshold) that a protein has on the average in the network. The clustering coefficient is a measure of how connected the nodes in the network are. Highly connected networks have high values.

The expected number of edges gives how many edges are to be expected if the nodes were to be selected at random. A small PPI enrichment p-value indicates that the nodes are not random and that the observed number of edges is significant.

\subsection{Cytokine expression in BALF}

BAL supernatants collected on $\mathrm{d} 0, \mathrm{~d} 3$ and $\mathrm{d} 180$ were analyzed using the Proteome Profiler ${ }^{\mathrm{TM}}$ Rat Cytokine Array Kit, Panel A (R\&D Systems, Minneapolis, MN) to determine released cytokine levels. Briefly, supernatants were incubated with a cocktail of biotinylated detection antibodies before 
applying the mixture onto nitrocellulose membranes spotted with immobilized antibodies specific for 29 selected rat cytokines and chemokines: CINC-1 (Cxcl1), CINC-2 $\alpha / \beta$ (Cxcl3), CINC-3 (Cxcl2), CNTF, Fractalkine (Cx3c11), GM-CSF, sICAM-1, IFN- $\gamma$, IL-1 $\alpha$, IL-1 $\beta$, IL-1ra, IL-2, IL-3, IL-4, IL-6, IL-10, IL-13, IL-17, IP-10 (Cxcl10), LIX (Cxcl5), L-Selectin, MIG (Cxc19), MIP-1 $\alpha$ (Ccl3), MIP-3 $\alpha$ (Cc120), RANTES (Cc15), Thymus chemokine (Cxcl7), TIMP-1, TNF- $\alpha$ and VEGF. Bound proteins were detected with streptavidin-conjugated horseradish peroxidase (HRP). Membranes were washed and developed using the Chemi Reagent $\mathrm{Mix}^{\mathrm{TM}}$; then read using a ChemiDoc ${ }^{\mathrm{TM}}$ Imager (Bio-Rad).

\subsection{Statistical analysis}

Statistical analysis of BALF cytological data was performed using a two-way ANOVA (both determinants being treatment and time). Data from the Proteome Profiler experiment were analyzed using a Student's t-test. Changes were considered statistically significant at $\mathrm{p}<0.05$.

\section{Results}

\subsection{BAL cytology and lung histopathology}

BAL cytology results have been extensively described previously [9]. Briefly, exposure to $\mathrm{TiO}_{2}$ aerosol triggered a strong increase of neutrophilic granulocytes up to $\mathrm{d} 3\left(0.01 \pm 0.005 \times 10^{6} v s .1 .06 \pm\right.$ $0.24 \times 10^{6}$ cells/left lung on $\mathrm{d} 0$ and $0.03 \pm 0.01 \times 10^{6} v s .1 .07 \pm 0.4 \times 10^{6}$ cells/left lung on $\mathrm{d} 3$ in control $v s$. exposed groups respectively). This influx decreased drastically but remained significant (p $<0.05)$ on d180 (26.2 $\pm 15.9 \times 10^{3}$ vs. $99.4 \pm 26.8 \times 10^{3}$ cells/left lung). Lymphocytes numbers were similar throughout the time course in control and exposed animals (data not shown). In addition, the number of alveolar macrophages was only increased in samples collected on $\mathrm{d} 3\left(0.85 \pm 0.08 \times 10^{6} \mathrm{vs}\right.$. $1.45 \pm 0.41 \times 10^{6}$ in control vs. exposed groups respectively). Histopathological analysis [9] showed that on $\mathrm{d} 0$ and $\mathrm{d} 3$, particle-laden macrophages were detected in the alveolar lumen from exposed animals. Moreover, proliferation of type II pneumocytes resulting in minimal epithelialization in alveolar walls and foci of granulomatous inflammation were observed in the alveoli of some exposed animals. On d180, in exposed animals, most of the particle-laden macrophages present in the alveolar lumen were limited to a few large aggregates, particularly next to the alveolar ducts and the terminal 
bronchioles with a minimal magnitude and a multifocal distribution. Alveolar wall surrounding these aggregates showed minimal epithelialization.

\subsection{MudPIT analysis}

As previously shown [9], total proteins in BALF were significantly increased in exposed animals on $\mathrm{d} 0$ and $\mathrm{d} 3(0.17 \pm 0.05 v s .0 .28 \pm 0.06 \mathrm{mg} / \mathrm{mL}$ on $\mathrm{d} 0$ and $0.12 \pm 0.04 v s .0 .25 \pm 0.04 \mathrm{mg} / \mathrm{mL}$ in controls and exposed animals respectively). These protein amounts were similar on d180 $(0.20 \pm 0.06$ vs. $0.20 \pm 0.03 \mathrm{mg} / \mathrm{mL}$ in controls and exposed animals respectively).

A chromatography-based proteomics technique named MudPIT, was performed on BALF. In BALF samples from controls and $\mathrm{TiO}_{2}$-exposed animals, 1848, 2237 and 1726 proteins were identified on $\mathrm{d} 0, \mathrm{~d} 3$ and $\mathrm{d} 180$ respectively. Statistical analysis of data revealed that among them 137, 78 and 51 $\underline{\text { ENSRNOP identifiers (Ensembl protein identifiers for Rattus norvegicus) }}$ were significantly differentially expressed $(\mathrm{p}<0.05)$ on $\mathrm{d} 0, \mathrm{~d} 3$ and $\mathrm{d} 180$, respectively.

On day 0, 116 out of 137 ENSRNOP identifiers were successfully mapped to 107 UniprotKB identifiers (Uniprot Knowledge Base) (Supplementary Table 1). On day 3, 58 out of 78 ENSRNOP identifiers were successfully mapped to 50 UniprotKB identifiers (Supplementary Table 2). On day 180, 45 out of 51 ENSRNOP identifiers were successfully mapped to 45 UniprotKB identifiers (Supplementary Table 3).

Functional analysis based on GO terms was performed using DAVID V6.7. Main common enriched GO BPs altered in BALF were related to proteolysis, inflammation, protein maturation, response to organic/inorganic substance, response to hormone stimulus, and cytoskeleton organization (Fig. 1). The levels of proteins involved in inflammatory response mainly increased in the short-term response phase. Among these proteins we found C4a, C4b, C4bpa, S100 Calcium Binding Protein A8 (S100a8), and Peroxiredoxin2 (Prdx2) (Supplementary Table $1 \&$ 2). On d180, proteins associated with inflammation such as Kininogen 1 (Kng1), Coagulation Factor II and XII (F2, F12), C8b, and Serpin family A member 3 (Serpina3n) were mainly decreased (Supplementary Table 3).

Concerning proteins involved in proteolysis, a process known to be activated during inflammation, Cathepsin S and D (Ctss, Ctsd), members of the proteasome complex such as Psma3, Psma4; were 
overexpressed in the short-term response phase (Supplementary Table $1 \& 2$ ). In contrast, on d180, other proteins such as C8b, F2, F12, Ctsb, Ctsc, Napsin A aspartic peptidase (Napsa) and Myosin heavy chain 9 (Myh9), were down-regulated compared to controls (Supplementary Table 3).

Another common biological process, altered after exposure to $\mathrm{TiO}_{2} \mathrm{NSA}$ in the short-term response phase, was related to cytoskeleton organization, with overexpression of various proteins such as Vimentin (Vim); Actin (Actn4, Actr3); CAP Adenylate cyclase-associated protein 1 (Cap1); Coronin 1A (Coro1A); Lymphocyte cytosolic protein 1 (Lcp1), Tubulin (Tuba3a, Tuba8, Tubb4); or downregulation of Gelsolin (Gsn) and Cofilin 2 (Cfl2) (Supplementary Table $1 \&$ 2). While on d180, Capping actin protein of muscle Z-line alpha subunit 1 (Capza1), Gsn, Lcp1, Myosin heavy chain 9 non-muscle (Myh9) and Superoxide dismutase 1 (Sod1), were down-regulated compared to controls. (Supplementary Table 3).

Enriched GO BP specifically modified in short- or long-term responses, are presented in Fig. 2. For instance, expression changes in the "proteasomal ubiquitin-dependent protein catabolic process" (upregulation of Psma3, Psma4, Psma6, Psmb4), cell cycle (up-regulation of Psma3-6, Psmb4, Psmb5, Psmb10, Ppp1ca-c, Tubb3), glucose metabolic process (up-regulation of Mdh2, Pgam1, Rpia, Pygl), were specific to the short-term response phase (Fig. 2A). In the long-term phase, 4 processes were specifically modified after exposure to $\mathrm{TiO}_{2} \mathrm{NSA}$ : response to drug, regulation of blood coagulation, response to cytokine stimulus, and lipid transport (Fig. 2B).

Moreover, proteins involved in oxidation-reduction process, such as Prdx5, Lpo, Mpo, Xdh and Vat1, were mainly up-regulated in exposed rats in the short-term response phase, whereas on d180, other proteins such as Sod1, Akr1a1 and Pdia3 were down-regulated compared to controls.

Interestingly, we also observed the up-regulation of various histones such as H1, H2A, H2B, H3 and $\mathrm{H} 4$, related to chromatin assembly, in the short-term response phase. On the other hand, 3 GO BP were enriched on day 0 and day 180 : "response to organic substance", "response to hormone stimulus" and "cytoskeleton organization". On day 3, some proteins involved in these GO BP were still differentially expressed, but these processes were not statistically enriched $(p>0.05)$ or didn't belong to annotation clusters with an Enrichment Score (Z score) greater than 1.3 [18]. 
On d0, KEGG biological pathways were significantly enriched $(\mathrm{p}<0.05)$; on $\mathrm{d} 3$ and $\mathrm{d} 180$; there were only 3 (Table 2). Like for GO BPs, KEGG pathways affected by inhalation of $\mathrm{TiO}_{2} \mathrm{NSA}$ in the short-term response phase, were mainly related to proteolysis (proteasome pathway), inflammation (complement and coagulation cascade pathway), and cytoskeleton organization (regulation of actin cytoskeleton; gap junction pathways including members of the alpha and beta tubulin protein family). On d180, complement and coagulation cascade pathway was still enriched, but the proteins involved were down-regulated in exposed rats compared to control rats.

To better understand the interactions between the differentially regulated proteins in response to $\mathrm{TiO}_{2}$ NSA exposure, the protein-protein networks were visualized on $\mathrm{d} 0, \mathrm{~d} 3$ and d180 using STRING database v10.5 (Fig. 3, 4 and 5).

On d0, 5 major networks were identified, related to the proteasome (key node proteins Psma3, Psma4, Psma5, Psma6, Psmb4, Psmb5, Psmb10), complement and coagulation cascades (key node proteins C3, C4a, C4bpa, Plg, Serpina1), glutathione metabolism (key node proteins Gpx1, Gss, Gstm2, Gstm4, Lap3), regulation of actin cytoskeleton (key node proteins Actn4, Arpc4, Arpc5, Cfl2, Gsn, Ppp1ca, Ppp1cc, Ppp1cb), and gap junction pathways (key node proteins Tuba3a, Tuba4a, Tuba8, Tubb3) (Fig. 3). We also observed a network including various histones (H1, H2 and H3) as mentioned above. Interestingly, these 6 networks interact directly with each other, or indirectly through other proteins.

On d3, 2 major networks were identified, related to the proteasome (key node proteins Psma3, Psma4, Psma6, Psma8, Psmb4), and complement and coagulation cascade pathways (key node proteins C1s, C4a, C4bpa) (Fig. 4). These 2 networks were however independent, without direct or indirect interactions.

On d180, only one major network was observed and was related to the complement and coagulation cascade pathway (key node proteins F2, F12, Kng1, Serpinc1) (Fig. 5).

Some brief statistics of the inferred network, such as the number of nodes and edges are presented in Table 3. It's worth noticing that small PPI enrichment p-values were observed on d0, d3 and d180 which indicated that the nodes were not random and that the observed number of edges was significant. On d0, d3 and d180, networks had significantly more interactions than expected. This 
means that proteins had more interactions among themselves than what would be expected from a random set of proteins of similar size, randomly drawn from the genome. Such enrichment indicates that the proteins, as a group, were at least partially biologically connected.

\subsection{Proteome profiler ${ }^{\mathrm{TM}}$ experiment}

The proteome profiler experiment indicated that 9 out of the 29 cytokines analyzed, were significantly differentially expressed in BALF on $\mathrm{d} 0(\mathrm{p}<0.05) ; 8$ of these proteins had increased levels including Cinc-1 (Cxcl1), Cinc-2 $\alpha / \beta$ (Cxcl3), Fractalkine (Cx3cl1), Lix (Cxcl5), and only one, Thymus chemokine 1 (Cxcl7) level was decreased in exposed rats (Fig. 6A). On d3, 9 cytokines were significantly up-regulated, out of which 6 were already overexpressed on d0: Cinc-1 (Cxcl1), Cinc2 $\alpha / \beta$ (Cxcl3), Lix (Cxc15), L-Selectin, Timp-1 and Vegf. Thymus chemokine 1 (Cxcl7), which was down-regulated on d0, was up-regulated on d3 (Fig. 6B). On d180, 4 proteins were significantly down-regulated compared to controls ( $\mathrm{p}<0.05)$ : Cinc-2 $\alpha / \beta(\mathrm{Cxcl} 3)$, Fractalkine $(\mathrm{Cx} 3 \mathrm{cl} 1)$, Lix $(\mathrm{Cxcl} 5)$ and Vegf, whereas as mentioned above, they were up-regulated at shorter post-exposure time points (Fig. 6C).

\section{Discussion}

\subsection{Exposure to $\mathrm{TiO}_{2} \mathrm{NSA}$}

For this study, rats were exposed 6 hours per day, 5 days a week for 4 weeks to $\mathrm{TiO}_{2} \mathrm{P} 25 \mathrm{NSA}$ at a concentration of $10 \mathrm{mg} / \mathrm{m}^{3}$. For such an aerosol (with a mass median aerodynamic diameter around $900 \mathrm{~nm}$ ), the pulmonary deposited fraction in rat measured by ICP-MS in a previous study was around $21 \%$ of the inhaled dose [20]. In human, the estimated pulmonary deposited fraction is around $11 \%$, according to Multiple-Path Particle Dosimetry Model (MPPD v3.04)

(https://www.ara.com/products/multiple-path-particle-dosimetry-model-mppd-v-304) using asymmetric PNNL human airway morphometries [21, 22]. Taking also into account the interspecies differences in terms of respiratory minute volumes, $0.23 \mathrm{~L} / \mathrm{min}$ for a Fischer 344 rat of $280 \mathrm{~g}$ [20] and 7.5 L/min for a man at rest (default values used by MPPD model v3.04), and total alveolar epithelial cell surface area of $0.4 \mathrm{~m}^{2}$ for rat and $102 \mathrm{~m}^{2}$ for human, the cumulated deposited dose normalized to 
alveolar cell surface area following animal exposure would be similar to the one following daily occupational exposure of a worker at $0.3 \mathrm{mg} / \mathrm{m}^{3}$ (the NIOSH recommended exposure limit for ultrafine $\mathrm{TiO}_{2}[11]$ ) throughout his career : 35 hours per week, 45 weeks per year for 20 years).

\subsection{Short-term response}

The strong pulmonary inflammatory response observed in the short-term response phase, was characterized by an increase in BALF total cells and neutrophils. Most studies focusing on the pulmonary response to inhaled/instilled $\mathrm{TiO}_{2}$ nanostructured particles in rats or mice $[2,23]$, highlighted lung inflammation characterized by an increase in BALF total cell and neutrophil counts, total protein content and enzyme activities [2, 7, 24-27].

As shown previously, animal exposure to $\mathrm{TiO}_{2}$ nanostructured particles also lead to an increase of BALF proteins probably associated with an impairment of the barrier between the alveolar wall and the blood capillaries leading to plasma proteins exudation in the alveolar space [9]. This process may be responsible for the significant increase of some proteins from the plasmatic origin, in the BALF of exposed animals. Proteomics analysis of BALF supernatant also revealed up-regulation of proteins associated with inflammation and immune response in the short-term phase, including protein S100a8, Ctss, Mpo, Cd177, Bpifb1, and a group of complement components: C4a, C4b, Cfb and C4bpa. To complete this analysis, an antibody array experiment performed on BALF supernatant confirmed the overexpression of numerous inflammatory cytokines, including Cxcl1, Cxcl3, Cxcl5. Moreover, deregulation of proteins involved in proteasome complex (such as Psma3, Psma4, Psma6, Psmb4); glucose metabolism (such as Pgam1, Pygl, Rpia, Eno2); chromatin assembly (up-regulation of various histones on $\mathrm{d} 0$ and d3); cytoskeleton organization (such as Vimentin, Actin, tubulin and Cofilin); oxidative stress (Lpo, Mpo, Prdx5, Mdh) and lipid metabolism (Pla2g1b, Sftpb, Plbd1); were observed. Taken together, these data are in agreement with in vitro and in vivo proteomics studies on $\mathrm{TiO}_{2}$ NPs showing deregulation of proteins involved in these various biological processes. They were found in A549 epithelial alveolar cells chronically exposed for 2 months to 2.5 or $50 \mu \mathrm{g} / \mathrm{mL}$ of $\mathrm{TiO}_{2^{-}}$ NPs [28], or exposed for $24 \mathrm{~h}$ to $0,60,140$ and $200 \mu \mathrm{g} / \mathrm{cm}^{2}$ of $\mathrm{TiO}_{2}(\mathrm{SRM}-154 \mathrm{~b})$ particles [29] and in human bronchial epithelial cell line (BEAS-2B) exposed for 24h to $\mathrm{BSA}$ coated $\mathrm{TiO}_{2}$ particles [30], or 
exposed to 10 or $100 \mu \mathrm{g} / \mathrm{mL}$ of $\mathrm{P} 25 \mathrm{TiO}_{2}$ nanoparticles [31]); as well as in lymph nodes of mice intradermally injected with a low dose of $\mathrm{P} 25 \mathrm{TiO}_{2}$ nanoparticles [32]).

The investigation of significantly enriched KEGG pathways and protein-protein interactions, revealed the presence of 7 enriched pathways and 5 major networks related to proteasome, complement and coagulation cascades, glutathione metabolism, regulation of actin cytoskeleton, and gap junction pathways. These pathways are all related to inflammation. Indeed, the ubiquitinproteasome system, the principal pathway of non-lysosomal proteolysis of intracellular proteins; is involved in the modulation of the immune and inflammatory responses [33]. Furthermore, glutathione metabolism participates in antioxidant defense systems that are involved in response to oxidative stress, induced by inflammation $[34,35]$.

During an inflammatory response, the recruitment and activation of neutrophils can cause oxidative stress. Here, we observed that the levels of some BALF proteins involved in this process were elevated following exposure to $\mathrm{TiO}_{2} \mathrm{NSA}$. Indeed, mass spectrometry analysis revealed increased levels of Lpo, Mpo, and anti-oxidant proteins Hspa1a, Hspa1b, Prdx5 in the short-term response phase. The latters are involved in ROS scavenging systems, suggesting that defense mechanisms against oxidative stress were triggered. However, despite their antioxidant activities, proteins from the superoxide dismutase family were not differentially expressed in the short-term response phase. As a whole our results are in good agreement with previous in vivo and in vitro studies indicated that $\mathrm{TiO}_{2} \mathrm{NPs}$ deposited into the lung trigger ROS production [1].

In addition enriched biological pathways found after $\mathrm{TiO}_{2}$ exposure such as oxidative stress, proteolysis, inflammatory response and cytoskeleton organization share similarities with those identified in chronic obstructive pulmonary disease (COPD) patients and smokers [36-38]. These results may suggest that a sustained exposure to $\mathrm{TiO}_{2} \mathrm{NP}$ level high enough to trigger chronic inflammation may lead to the development of pulmonary pathologies.

Interestingly, mass spectrometry-based proteomics analysis of BALF showed increased levels of a number of histone isoforms on $\mathrm{d} 0$ and $\mathrm{d} 3$ : Histones $\mathrm{H} 1.4, \mathrm{H} 2 \mathrm{~A}, \mathrm{H} 2 \mathrm{~B}$ and $\mathrm{H} 4$. Histones are intracellular proteins involved in nucleosome assembly. However, these proteins can also be released in the extracellular space by neutrophils during the neutrophil extracellular traps (NET) formation 
1 [39], or through neutrophil-mediated cell damage and death [40, 41]. Indeed, neutrophils are recruited

2 to the site of injury, to recognize and phagocyte pathogens through various cytotoxic mechanisms;

3 such as ROS production, release of antimicrobial peptides and expulsion of their nuclear contents to

4 form NET [42]. NET formation or NETosis is considered to be the main source of extracellular

5 histones [39].

$6 \quad$ NET are composed of decondensed chromatin fibers coated with antimicrobial proteins such as neutrophil Elastase, Myeloperoxidase (Mpo) or Lysozyme. In 2009, a proteomic analysis identified 24 NET-associated proteins in human peripheral blood neutrophils including histones [41]. In our study, 7 out of these 24 proteins were found in BALF supernatant of exposed rats: histones H2A, H2B, H4, Mpo, Lysozyme, S100a8 and alpha-actinin 4 [39-41]. This might be explained by the sensitivity of our method or the way samples were collected which did not allow identifying all the differentially expressed extracellular proteins present in the BALF especially those with low abundance.

NET release induced by nanoparticles was described in vitro with human primary immune cells exposed to gold nanoparticles [43]. Another study reported disturbance in NETosis and oxidative burst induced by $\mathrm{TiO}_{2}$ NPs [44] both in vivo on fathead minnow fish (Pimpehales promelas), and in vitro using cell suspension obtained from adult fish kidneys. Recently, it has been suggested that $15-\mathrm{nm}$ silver NPs also induce NET release from human polymorphonuclear neutrophils isolated from venous blood of healthy volunteers [45].

Although NET formation is involved in neutrophil host defense functions, excessive NET release can cause tissue damage, stimulation of undesirable immune reactions, and is associated with various pulmonary diseases such as acute lung injury, asthma, cystic fibrosis, chronic obstructive pulmonary disease $[42,46]$. NET associated proteins were also found in BALF from Calves infected by bovine respiratory syncytial virus [47] suggesting that pulmonary mechanisms involved in the defense against foreign nanomaterials share common pathways with those involved with viruses._Here, this possible NET release occurs in an inflammatory context but in the absence of significant histopathological changes. Indeed, as previously described, neither epithelial cell apoptosis/necrosis in lung epithelial cells, nor fibrosis in the airways was observed [9]. In addition, NET release was only observed in the 
acute phase suggesting that it was associated the strong inflammatory response which disappears overtime.

Further experiments are required to better characterize the source of extracellular histones in BALF such as immunostaining which can visualize the co-localization of chromatin and granule proteins such as Mpo [42]. Nevertheless, taken together, these findings could be linked to the stimulation of NET formation in rat lung following nose-only exposure to $\mathrm{TiO}_{2} \mathrm{NSA}$ which, to the best of our knowledge, has not been described before.

\subsection{Long-term response}

Activation of defense mechanisms immediately after the exposure to nanomaterials is a physiological process. However, the long-term consequences of this type of exposure raise concerns since it may lead to various pulmonary pathologies $[1,48]$. The amount of titanium (measured by ICP-MS) found in the lung of the exposed animals at $\mathrm{d} 0$ was about $2.1 \mathrm{mg} / \mathrm{lung}$ [20]. It decreased overtime and reached $35 \%$ of the starting amount on $\mathrm{d} 180$. This results suggest that a significant amount of particles were still present in the lung 180 days after the end of exposure but had limited physiopathological effects. An inflammatory response was still present, however, at a much lower intensity than in the short-term response. It was associated with the presence of particles-laden macrophages. But, as previously described, despite the presence of remaining nanoparticles in the lung, no significant histopathological change was observed [9].

On d180, most of the proteins with altered expression in BALF supernatant, as assessed by mass spectrometry, were down-regulated compared to controls, except for Trem2 (Triggering receptor expressed on myeloid cells 2), Cd177 antigen-like and an uncharacterized protein involved in inflammation. Three enriched pathways and one major interaction network (complement and coagulation cascades pathway), were still observed, related to the persistence of a low intensity inflammatory response. Additionally, a slight but significant down-regulation of Vegf and 3 inflammatory chemokines (Cxcl3, C3xcl1, Cxc15) was detected in BALF. Vegf is secreted by alveolar macrophages to initiate repair of the endothelial barrier following lung inflammation; $\mathrm{Cxcl} 3$ and $\mathrm{Cxcl} 5$ are involved in the recruitment and activation of neutrophils to alveolar spaces [49, 50]. Down- 
regulation of some chemokines in exposed rats on d180 might be related to the decrease in BALF neutrophils in long term response, supporting a progressive resolution of inflammation and potential lung recovery [9], related to the decrease of the Ti lung burden [20]. These data are consistent with the fact that $\mathrm{TiO}_{2}$ nanoparticles are low toxicity, low solubility nanomaterials and clearly show that defense mechanisms initiated during the exposure to aerosol were effective to circumvent any longterm adverse effects that could been induced by these nanomaterial despite the relatively high initial pulmonary deposited dose.

During the inflammatory response, excessive ROS production leads to the development of oxidative stress. In BALF, some proteins involved in oxidative stress (Hspa1a, Hspa1b and Sod1) were down-regulated on d180 in exposed rats compared to control rats. As mentioned above, these results suggest a progressive resolution of oxidative stress in the long-term response phase associated with the presence of few remaining inflammatory cells.

\subsection{Comparison of proteomic and transcriptomic data in short- and long-term responses}

A previous study using transcriptomic analysis was performed on rat lungs [9]. Comparing these results with our present proteomics work, we noticed a common overexpression transcripts and proteins from genes involved in inflammatory and immune responses, complement and coagulation cascades, and oxidative stress. Among those, chemokines (Cxcl1, C3xcl1, Cxcl5), and others like Cd177, C4bpa, Lpo, Chia and Tuba8 were identified [9]. Six months after the end of exposure, despite the fact that the number of inflammatory cells had decreased; many genes and proteins remained differentially expressed.

These data tend to show a link between transcriptomic and proteomic data suggesting that the change in the expression of some genes in the lung leads to the secretion of proteins in the alveolar space where they could play a role in the defense mechanisms activated following $\mathrm{TiO}_{2}$ exposure.

\section{Conclusion}

This in vivo study brings new insight about the short- and long-term pulmonary effects (up to 6month post-exposure) of inhaled nanostructured $\mathrm{TiO}_{2}$ aerosol through the combination of BALF 
cytology and proteomics analyses. Exposure to $\mathrm{TiO}_{2}$ NSA resulted in a strong acute inflammatory response in the lung. This response was characterized by a neutrophil influx, associated with an overexpression of proteins involved in proteasome, inflammatory and immune responses, complement and coagulation cascade, oxidative stress, and cytoskeleton organization in the short-term response phase. In the BALF supernatant, the increased level of histones and other NET-associated proteins suggests the release of NET in the alveolar space. This possible NET release occurs in an inflammatory context but in the absence of significant histopathological changes.

Six months after the end of exposure (long-term response), inflammation had decreased, but many proteins remained differentially expressed; mainly down-regulated in exposed rats compared to control rats. These observations suggest a progressive resolution of inflammation and potential lung recovery.

We observed changes in processes such as inflammation and cardiovascular system. These 2 processes are linked especially via Kng1, also known as HMWK-kallikrein factor, which expression was altered on d180. Thus, Kng1 might be a good candidate biomarker for monitoring the pulmonary toxicity induced by nanomaterials, although this hypothesis needs to be further investigated.

\section{Conflicts of interest}

The authors declare that they have no competing interests.

\section{Acknowledgements}

This work has been supported by the National Fund for the Prevention of Occupational Accidents and Diseases.

The authors gratefully acknowledge Aurélie Remy for her help with statistical analysis, Stéphane Grossmann and Hervé Nunge for aerosol generation and characterization, Sylvie Sébillaud, Mylène Lorcin and Cristina Langlais for tissue sampling and BAL cell count, and Sylvie Michaux, MarieJosèphe Décret and Laurine Douteau for animal care and husbandry. Nathalie Quintero is acknowledged for her help with the mass spectrometry work performed at the Vincent J. Coates Proteomics/Mass Spectrometry Laboratory (UC Berkeley, CA). 


\section{References:}

[1] Shi H, Magaye R, Castranova V, Zhao J. Titanium dioxide nanoparticles: a review of current toxicological data. Part Fibre Toxicol. 2013;10:15.

[2] Bermudez E, Mangum JB, Wong BA, Asgharian B, Hext PM, Warheit DB, et al. Pulmonary responses of mice, rats, and hamsters to subchronic inhalation of ultrafine titanium dioxide particles. Toxicol Sci. 2004;77:347-57.

[3] Halappanavar S, Saber AT, Decan N, Jensen KA, Wu D, Jacobsen NR, et al. Transcriptional profiling identifies physicochemical properties of nanomaterials that are determinants of the in vivo pulmonary response. Environ Mol Mutagen. 2015;56:245-64.

[4] Sturla SJ, Boobis AR, FitzGerald RE, Hoeng J, Kavlock RJ, Schirmer K, et al. Systems toxicology: from basic research to risk assessment. Chem Res Toxicol. 2014;27:314-29.

[5] Husain M, Saber AT, Guo C, Jacobsen NR, Jensen KA, Yauk CL, et al. Pulmonary instillation of low doses of titanium dioxide nanoparticles in mice leads to particle retention and gene expression changes in the absence of inflammation. Toxicol Appl Pharmacol. 2013;269:250-62.

[6] Nikota J, Williams A, Yauk CL, Wallin H, Vogel U, Halappanavar S. Meta-analysis of transcriptomic responses as a means to identify pulmonary disease outcomes for engineered nanomaterials. Part Fibre Toxicol. 2016;13:25.

[7] Rahman L, Wu D, Johnston M, William A, Halappanavar S. Toxicogenomics analysis of mouse lung responses following exposure to titanium dioxide nanomaterials reveal their disease potential at high doses. Mutagenesis. 2017;32:59-76.

[8] Husain M, Wu D, Saber AT, Decan N, Jacobsen NR, Williams A, et al. Intratracheally instilled titanium dioxide nanoparticles translocate to heart and liver and activate complement cascade in the heart of C57BL/6 mice. Nanotoxicology. 2015;9:1013-22.

[9] Chezeau L, Sebillaud S, Safar R, Seidel C, Dembele D, Lorcin M, et al. Short- and long-term gene expression profiles induced by inhaled $\mathrm{TiO} 2$ nanostructured aerosol in rat lung. Toxicol Appl Pharmacol. 2018;356:54-64.

[10] Cosnier F, Bau S, Grossmann S, Nunge H, Brochard C, Viton S, et al. Design and Characterization of an Inhalation System to Expose Rodents to Nanoaerosols. Aerosol and Air Quality Research. 2016;12:2989-3000.

[11] NIOSH. Occupational Exposure to Titanium Dioxide Current Intelligence. National Institute for Occupational Safety and Health. 2011;Bulletin 63.

[12] OECD. "OECD Guidelines for the Testing of Chemicals. Test No. 412: Subacute Inhalation Toxicity: 28-Day Study.". Organization for Economic Co-operation and Development Guidelines for the Testing of Chemicals.; 2017.

[13] Fuchs G, Diges C, Kohlstaedt LA, Wehner KA, Sarnow P. Proteomic analysis of ribosomes: translational control of mRNA populations by glycogen synthase GYS1. J Mol Biol. 2011;410:118-30. [14] Xu T, Park SK, Venable JD, Wohlschlegel JA, Diedrich JK, Cociorva D, et al. ProLuCID: An improved SEQUEST-like algorithm with enhanced sensitivity and specificity. J Proteomics. 2015;129:16-24.

[15] Peng J, Elias JE, Thoreen CC, Licklider LJ, Gygi SP. Evaluation of multidimensional chromatography coupled with tandem mass spectrometry (LC/LC-MS/MS) for large-scale protein analysis: the yeast proteome. J Proteome Res. 2003;2:43-50.

[16] McIlwain S, Mathews M, Bereman MS, Rubel EW, MacCoss MJ, Noble WS. Estimating relative abundances of proteins from shotgun proteomics data. BMC Bioinformatics. 2012;13:308. [17] Zybailov B, Mosley AL, Sardiu ME, Coleman MK, Florens L, Washburn MP. Statistical analysis of membrane proteome expression changes in Saccharomyces cerevisiae. J Proteome Res. 2006;5:2339-47.

[18] Huang DW, Sherman BT, Lempicki RA. Systematic and integrative analysis of large gene lists using DAVID bioinformatics resources. Nat Protoc. 2009;4:44-57.

[19] Szklarczyk D, Franceschini A, Wyder S, Forslund K, Heller D, Huerta-Cepas J, et al. STRING v10: protein-protein interaction networks, integrated over the tree of life. Nucleic Acids Res. 2015;43:D447-52. 
[20] Gate L, Disdier C, Cosnier F, Gagnaire F, Devoy J, Saba W, et al. Biopersistence and translocation to extrapulmonary organs of titanium dioxide nanoparticles after subacute inhalation exposure to aerosol in adult and elderly rats. Toxicol Lett. 2017;265:61-9.

[21] Anjilvel S, Asgharian B. A multiple-path model of particle deposition in the rat lung. Fundam Appl Toxicol. 1995;28:41-50.

[22] Miller FJ, Asgharian B, Schroeter JD, Price O. Improvements and additions to the Multiple Path Particle Dosimetry model. Journal of Aerosol Science. 2016;99:14-26.

[23] Bermudez E, Mangum JB, Asgharian B, Wong BA, Reverdy EE, Janszen DB, et al. Long-term pulmonary responses of three laboratory rodent species to subchronic inhalation of pigmentary titanium dioxide particles. Toxicol Sci. 2002;70:86-97.

[24] Halappanavar S, Jackson P, Williams A, Jensen KA, Hougaard KS, Vogel U, et al. Pulmonary response to surface-coated nanotitanium dioxide particles includes induction of acute phase response genes, inflammatory cascades, and changes in microRNAs: a toxicogenomic study. Environ Mol Mutagen. 2011;52:425-39.

[25] Ma-Hock L, Burkhardt S, Strauss V, Gamer AO, Wiench K, van Ravenzwaay B, et al. Development of a short-term inhalation test in the rat using nano-titanium dioxide as a model substance. Inhal Toxicol. 2009;21:102-18.

[26] Nurkiewicz TR, Porter DW, Barger M, Millecchia L, Rao KM, Marvar PJ, et al. Systemic microvascular dysfunction and inflammation after pulmonary particulate matter exposure. Environ Health Perspect. 2006;114:412-9.

[27] Warheit DB, Webb TR, Reed KL, Frerichs S, Sayes CM. Pulmonary toxicity study in rats with three forms of ultrafine-TiO2 particles: differential responses related to surface properties. Toxicology. 2007;230:90-104.

[28] Armand L, Biola-Clier M, Bobyk L, Collin-Faure V, Diemer H, Strub JM, et al. Molecular responses of alveolar epithelial A549 cells to chronic exposure to titanium dioxide nanoparticles: A proteomic view. J Proteomics. 2016;134:163-73.

[29] Vuong NQ, Goegan P, Mohottalage S, Breznan D, Ariganello M, Williams A, et al. Proteomic changes in human lung epithelial cells (A549) in response to carbon black and titanium dioxide exposures. J Proteomics. 2016;149:53-63.

[30] Cha MH, Rhim T, Kim KH, Jang AS, Paik YK, Park CS. Proteomic identification of macrophage migration-inhibitory factor upon exposure to TiO2 particles. Mol Cell Proteomics. 2007;6:56-63. [31] Ge Y, Bruno M, Wallace K, Winnik W, Prasad RY. Proteome profiling reveals potential toxicity and detoxification pathways following exposure of BEAS-2B cells to engineered nanoparticle titanium dioxide. Proteomics. 2011;11:2406-22.

[32] Gao Y, Gopee NV, Howard PC, Yu LR. Proteomic analysis of early response lymph node proteins in mice treated with titanium dioxide nanoparticles. J Proteomics. 2011;74:2745-59.

[33] Wang J, Maldonado MA. The ubiquitin-proteasome system and its role in inflammatory and autoimmune diseases. Cell Mol Immunol. 2006;3:255-61.

[34] Khansari N, Shakiba Y, Mahmoudi M. Chronic inflammation and oxidative stress as a major cause of age-related diseases and cancer. Recent Pat Inflamm Allergy Drug Discov. 2009;3:73-80. [35] Rogers KR, Morris CJ, Blake DR. The cytoskeleton and its importance as a mediator of inflammation. Ann Rheum Dis. 1992;51:565-71.

[36] Rollet-Cohen V, Bourderioux M, Lipecka J, Chhuon C, Jung VA, Mesbahi M, et al. Comparative proteomics of respiratory exosomes in cystic fibrosis, primary ciliary dyskinesia and asthma. $\mathrm{J}$ Proteomics. 2018;185:1-7.

[37] Yang M, Kohler M, Heyder T, Forsslund H, Garberg HK, Karimi R, et al. Long-term smoking alters abundance of over half of the proteome in bronchoalveolar lavage cell in smokers with normal spirometry, with effects on molecular pathways associated with COPD. Respir Res. 2018;19:40.

[38] Yang M, Kohler M, Heyder T, Forsslund H, Garberg HK, Karimi R, et al. Proteomic profiling of lung immune cells reveals dysregulation of phagocytotic pathways in female-dominated molecular COPD phenotype. Respir Res. 2018;19:39.

[39] Daigo K, Takamatsu Y, Hamakubo T. The Protective Effect against Extracellular Histones Afforded by Long-Pentraxin PTX3 as a Regulator of NETs. Front Immunol. 2016;7:344.

[40] Ward PA, Grailer JJ. Acute lung injury and the role of histones. Transl Respir Med. 2014;2:1. 
[41] Urban CF, Ermert D, Schmid M, Abu-Abed U, Goosmann C, Nacken W, et al. Neutrophil extracellular traps contain calprotectin, a cytosolic protein complex involved in host defense against Candida albicans. PLoS Pathog. 2009;5:e1000639. [42] Mayadas TN, Cullere X, Lowell CA. The multifaceted functions of neutrophils. Annu Rev Pathol. 2014;9:181-218.

[43] Bartneck M, Keul HA, Zwadlo-Klarwasser G, Groll J. Phagocytosis independent extracellular nanoparticle clearance by human immune cells. Nano Lett. 2010;10:59-63.

[44] Jovanovic B, Anastasova L, Rowe EW, Zhang Y, Clapp AR, Palic D. Effects of nanosized titanium dioxide on innate immune system of fathead minnow (Pimephales promelas Rafinesque, 1820). Ecotoxicol Environ Saf. 2011;74:675-83.

[45] Liz R, Simard JC, Leonardi LB, Girard D. Silver nanoparticles rapidly induce atypical human neutrophil cell death by a process involving inflammatory caspases and reactive oxygen species and induce neutrophil extracellular traps release upon cell adhesion. Int Immunopharmacol. 2015;28:61625.

[46] Porto BN, Stein RT. Neutrophil Extracellular Traps in Pulmonary Diseases: Too Much of a Good Thing? Front Immunol. 2016;7:311.

[47] Hagglund S, Blodorn K, Naslund K, Vargmar K, Lind SB, Mi J, et al. Proteome analysis of bronchoalveolar lavage from calves infected with bovine respiratory syncytial virus-Insights in pathogenesis and perspectives for new treatments. PLoS One. 2017;12:e0186594.

[48] Song B, Zhou T, Yang W, Liu J, Shao L. Contribution of oxidative stress to TiO2 nanoparticleinduced toxicity. Environ Toxicol Pharmacol. 2016;48:130-40.

[49] Herold S, Mayer K, Lohmeyer J. Acute lung injury: how macrophages orchestrate resolution of inflammation and tissue repair. Front Immunol. 2011;2:65.

[50] Aggarwal NR, King LS, D'Alessio FR. Diverse macrophage populations mediate acute lung inflammation and resolution. Am J Physiol Lung Cell Mol Physiol. 2014;306:L709-25. 


\begin{tabular}{cccccc}
\hline $\begin{array}{c}\text { Particle size } \\
(\mathbf{n m})\end{array}$ & $\begin{array}{c}\text { Specific surface area } \\
\left(\mathbf{m}^{2} / \mathbf{g}\right)\end{array}$ & $\begin{array}{c}\text { Aerosol mass } \\
\text { concentration } \\
\left(\mathbf{m g} / \mathbf{m}^{\mathbf{3}}\right)\end{array}$ & $\begin{array}{c}\text { Aerosol number } \\
\text { concentration } \\
\left(\mathbf{p a r t i c l e} / \mathbf{c m}^{3}\right)\end{array}$ & CMAD (nm) & MMAD (nm) \\
\hline $21.5 \pm 7.2$ & 51 & $10.17 \pm 3.29$ & $24000 \pm 6400$ & 269 & 905 \\
& & & & $(\mathrm{GSD}: 2.22)$ & $(\mathrm{GSD}: 2.19)$ \\
\hline
\end{tabular}

Table 2: Significantly enriched biological pathways in $\mathrm{BALF}$ of rats exposed to $\mathrm{TiO}_{2}$ nanostructured aerosol, on post-exposure days 0,3 and 180 (p-value $<0.05$ ).

\begin{tabular}{|c|c|c|c|}
\hline KEGG Pathways & $\begin{array}{l}\text { Number of } \\
\text { genes }\end{array}$ & p-value & Proteins \\
\hline \multicolumn{4}{|l|}{ Day 0} \\
\hline Proteasome & 8 & $3.3447 \mathrm{E}-7$ & $\begin{array}{l}\text { PSMB10, PSMB5, PSMB4, PSMA6, PSMA5, } \\
\text { PSMA4, PSMA3, RGD1564425 }\end{array}$ \\
\hline $\begin{array}{l}\text { Complement and } \\
\text { coagulation cascades }\end{array}$ & 6 & $4.7987 \mathrm{E}-4$ & CFB, C4B, C3, SERPINA1, C4BPA, PLG \\
\hline Glutathione metabolism & 5 & 0.0012 & GSS, LAP3, GPX1, GSTM2, GSTM4 \\
\hline $\begin{array}{l}\text { Systemic lupus } \\
\text { erythematosus }\end{array}$ & 6 & 0.0015 & $\begin{array}{l}\text { ACTN4, HIST1H4B, C4B, C3, HIST2H2BE, } \\
\text { HIST3H2BA }\end{array}$ \\
\hline $\begin{array}{l}\text { Regulation of actin } \\
\text { cytoskeleton }\end{array}$ & 8 & 0.0032 & $\begin{array}{l}\text { PPP1CA, ACTN4, GSN, CFL2, ARPC4, } \\
\text { ARPC5, PPP1CC, PPP1CB }\end{array}$ \\
\hline Oocyte meiosis & 5 & 0.0204 & PPP1CA, PPP2CA, PPP2CB, PPP1CC, PPP1CB \\
\hline Gap junction & 4 & 0.0408 & TUBA8, TUBA3A, TUBA4A, TUBB3 \\
\hline \multicolumn{4}{|l|}{ Day 3} \\
\hline Proteasome & 4 & $3.4747 \mathrm{E}-4$ & PSMB4, PSMA6, PSMA4, PSMA3 \\
\hline $\begin{array}{l}\text { Complement and } \\
\text { coagulation cascades }\end{array}$ & 4 & $9.3708 \mathrm{E}-4$ & $\mathrm{CFB}, \mathrm{C} 4 \mathrm{~B}, \mathrm{C} 1 \mathrm{~S}, \mathrm{C} 4 \mathrm{BPA}$ \\
\hline $\begin{array}{l}\text { Systemic lupus } \\
\text { erythematosus }\end{array}$ & 3 & 0.0265 & HIST1H4B, C4B, C1S \\
\hline \multicolumn{4}{|l|}{ Day 180} \\
\hline $\begin{array}{l}\text { Complement and } \\
\text { coagulation cascades }\end{array}$ & 6 & $2.7045 \mathrm{E}-6$ & KNG1, C8B, F12, C4B, F2, SERPINC1 \\
\hline Prion diseases & 3 & 0.0060 & C8B, HSPA1A, HSPA1B, SOD1 \\
\hline $\begin{array}{l}\text { Antigen processing and } \\
\text { presentation }\end{array}$ & 3 & 0.0352 & PDIA3, HSPA1A, CTSB, HSPA1B \\
\hline
\end{tabular}

Table 3: Brief statistics of the inferred network calculated on post-exposure days 0,3 and 180 (String database V10.5).

\begin{tabular}{llll}
\hline & \multicolumn{3}{l}{ Post-exposure days } \\
\hline & 0 & 3 & 180 \\
\hline Number of nodes & 101 & 43 & 40 \\
Number of edges & 204 & 26 & 19 \\
Average node degree & 4.04 & 1.21 & 0.95 \\
Average local clustering coefficient & 0.526 & 0.326 & 0.395 \\
Expected number of edges & 73 & 4 & 6 \\
PPI enrichment p-value & $<1.0 \mathrm{e}-16$ & $1.17 \mathrm{e}-12$ & $1.57 \mathrm{e}-05$ \\
\hline
\end{tabular}




\section{Figures}

Fig.1 Common enriched Gene Ontology Biological Processes (GO BP) modified in BALF of rats exposed to $\mathrm{TiO}_{2}$ nanostructured aerosol immediately, 3 and 180 days after the end of exposure. They were determined through DAVID bioinformatics Resources 6.7 with a $\mathrm{Z}$ score $>1.3$ or a pvalue $<0.05$.

Fig.2 Enriched GO BP specifically modified in the short- (A) or long-term (B) response phase in BALF of rats exposed to $\mathrm{TiO}_{2}$ nanostructured aerosol. ( $\mathrm{Z}$ score $>1.3$ or $\mathrm{p}<0.05$ ).

Fig.3 The STRING network of protein-protein interactions in BALF of rats exposed to $\mathrm{TiO}_{2}$ nanostructured aerosol, immediately after the end of exposure. List of all differentially regulated proteins in BALF of rats exposed to $\mathrm{TiO}_{2}$ nanostructured aerosol, immediately after the end of exposure ( $\mathrm{p}<0.05)$ (Supplementary Table 1) were injected in STRING database v10.5. Some significantly enriched KEGG pathways (determined using DAVID database) are represented in the boxes. Legend: Network nodes represent proteins, edges represent protein-protein associations (red line: presence of fusion evidence, green line: neighborhood evidence, blue line: co-occurrence evidence, purple line: experimental evidence, yellow line: text mining evidence, light blue line: database evidence, black line: co-expression evidence).

Fig.4 The STRING network of protein-protein interactions in BALF of rats exposed to $\mathrm{TiO}_{2}$ nanostructured aerosol, on post-exposure day 3. List of all differentially regulated proteins in BALF of rats exposed to $\mathrm{TiO}_{2}$ nanostructured aerosol, on post-exposure day $3(\mathrm{p}<0.05)$ (Supplementary Table 2) were injected in STRING database v10.5. Some significantly enriched KEGG pathways (determined using DAVID database) are represented in the boxes.

Fig.5 The STRING network of protein-protein interactions in BALF of rats exposed to $\mathrm{TiO}_{2}$ nanostructured aerosol, on post-exposure day 180. List of all differentially regulated proteins in BALF of rats exposed to $\mathrm{TiO}_{2}$ nanostructured aerosol, on post-exposure day $180(\mathrm{p}<0.05)$ (Supplementary Table 3) were injected in STRING database v10.5. One significantly enriched KEGG pathway (determined using DAVID database) is represented in the boxes.

Fig.6 Significantly expressed cytokines in BALF of exposed animals. Expression level of 29 cytokines was analyzed in control and exposed rats to $\mathrm{TiO}_{2}$ nanostructured aerosol in BALF on post-exposure days 0,3 and 180 . Only differentially expressed proteins $(\mathrm{p}<0.05)$ are presented. 


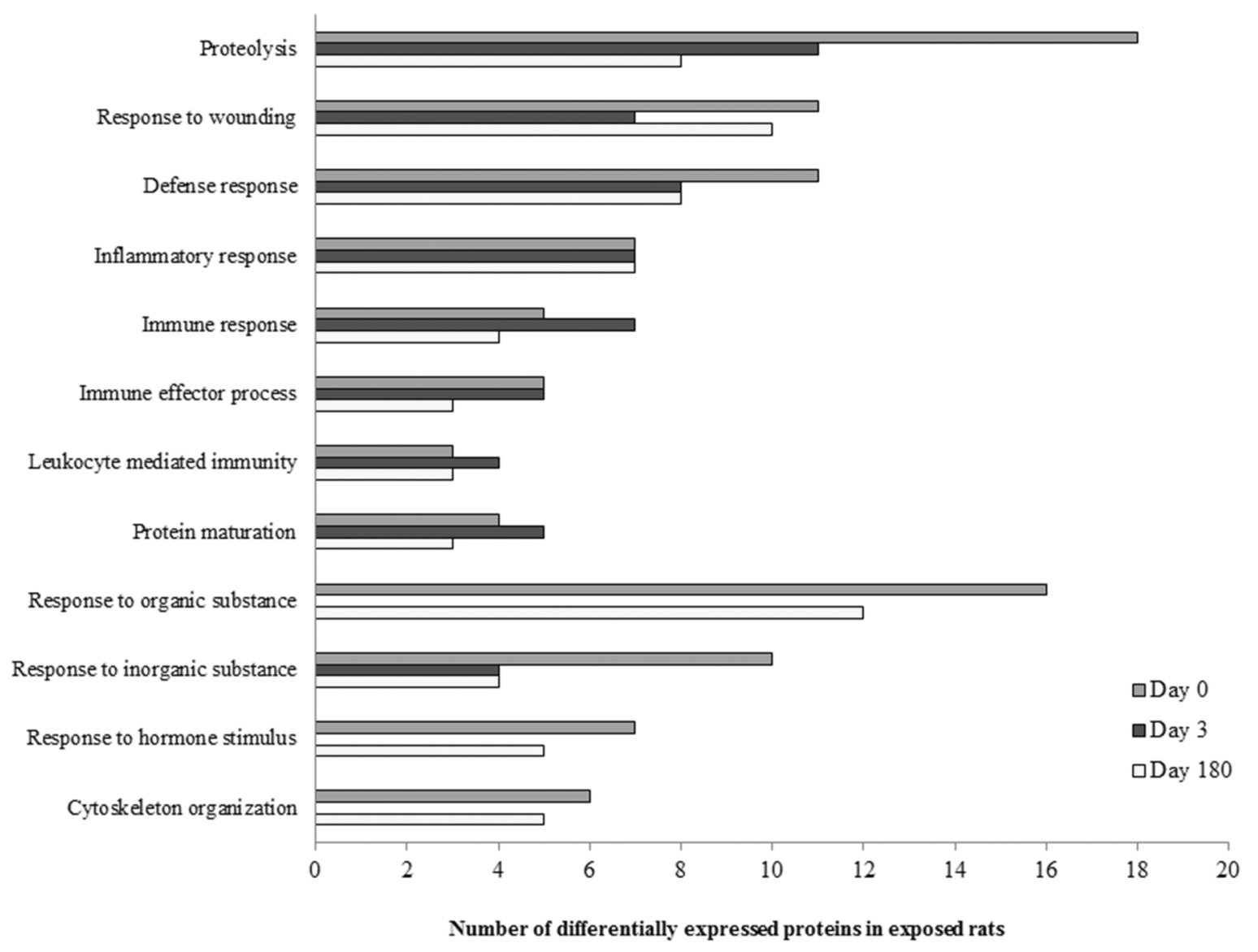


Negative regulation of molecular function

Protein catabolic process

Proteasomal ubiquitin-dependent protein catabolic process

$$
\text { Cell cycle }
$$

Glucose metab olic process
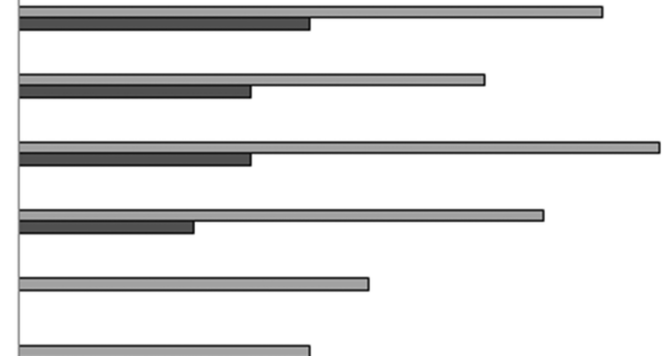
Response to bacterium
Protein amino acid dephosphorylation

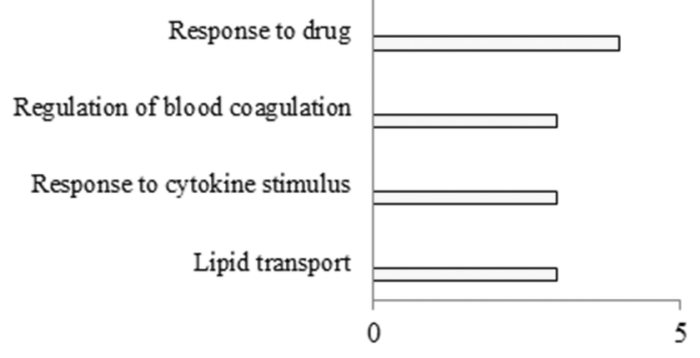




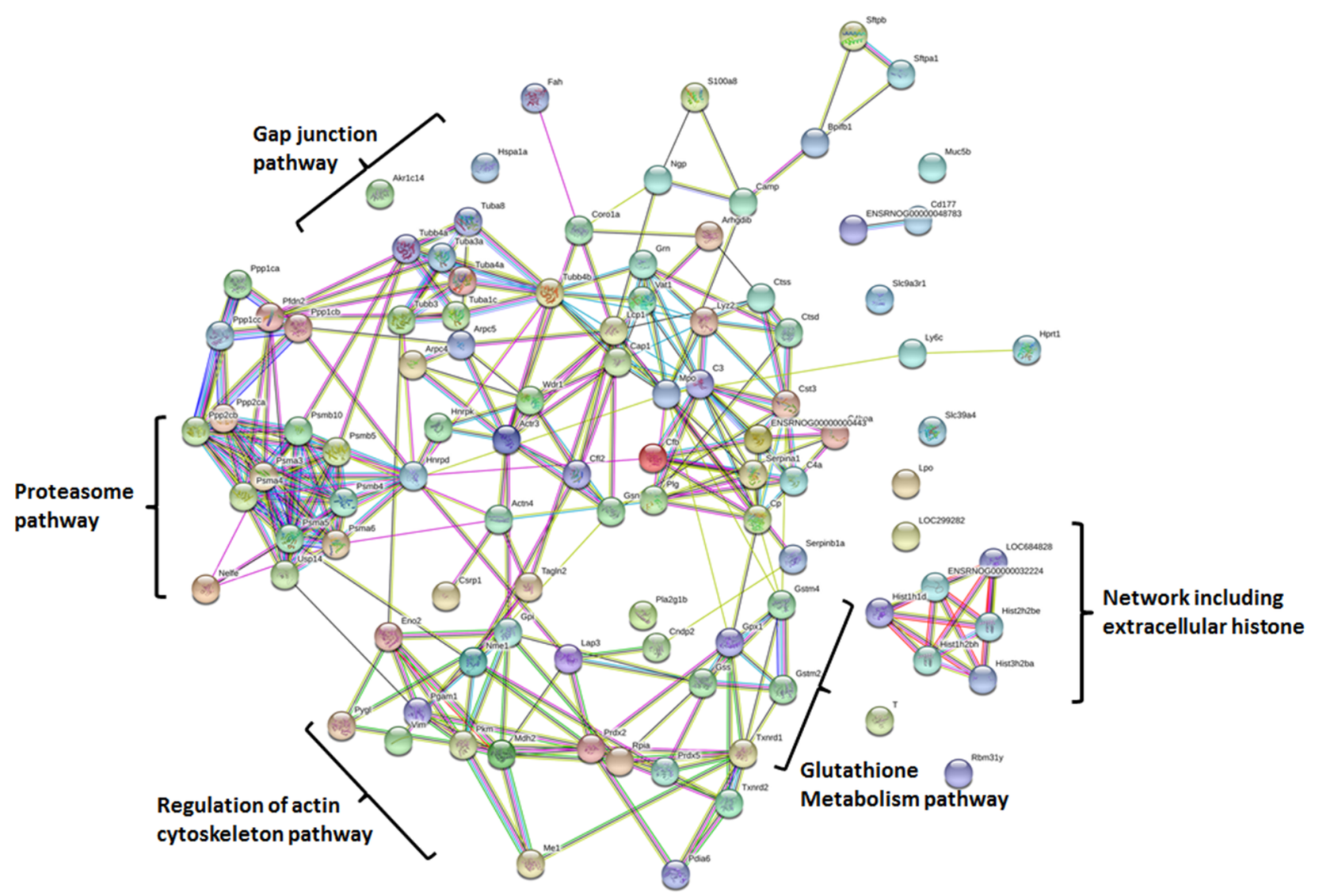




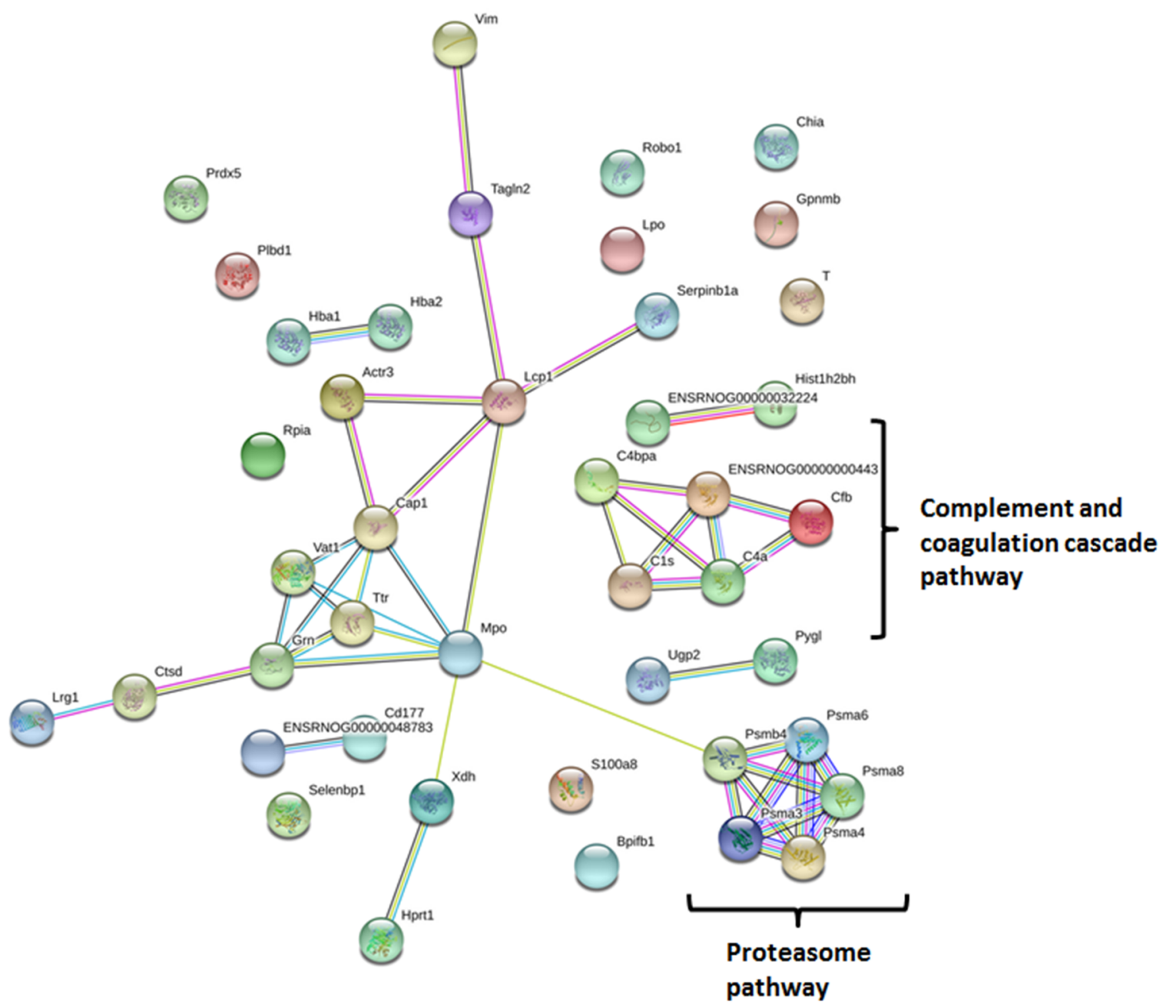




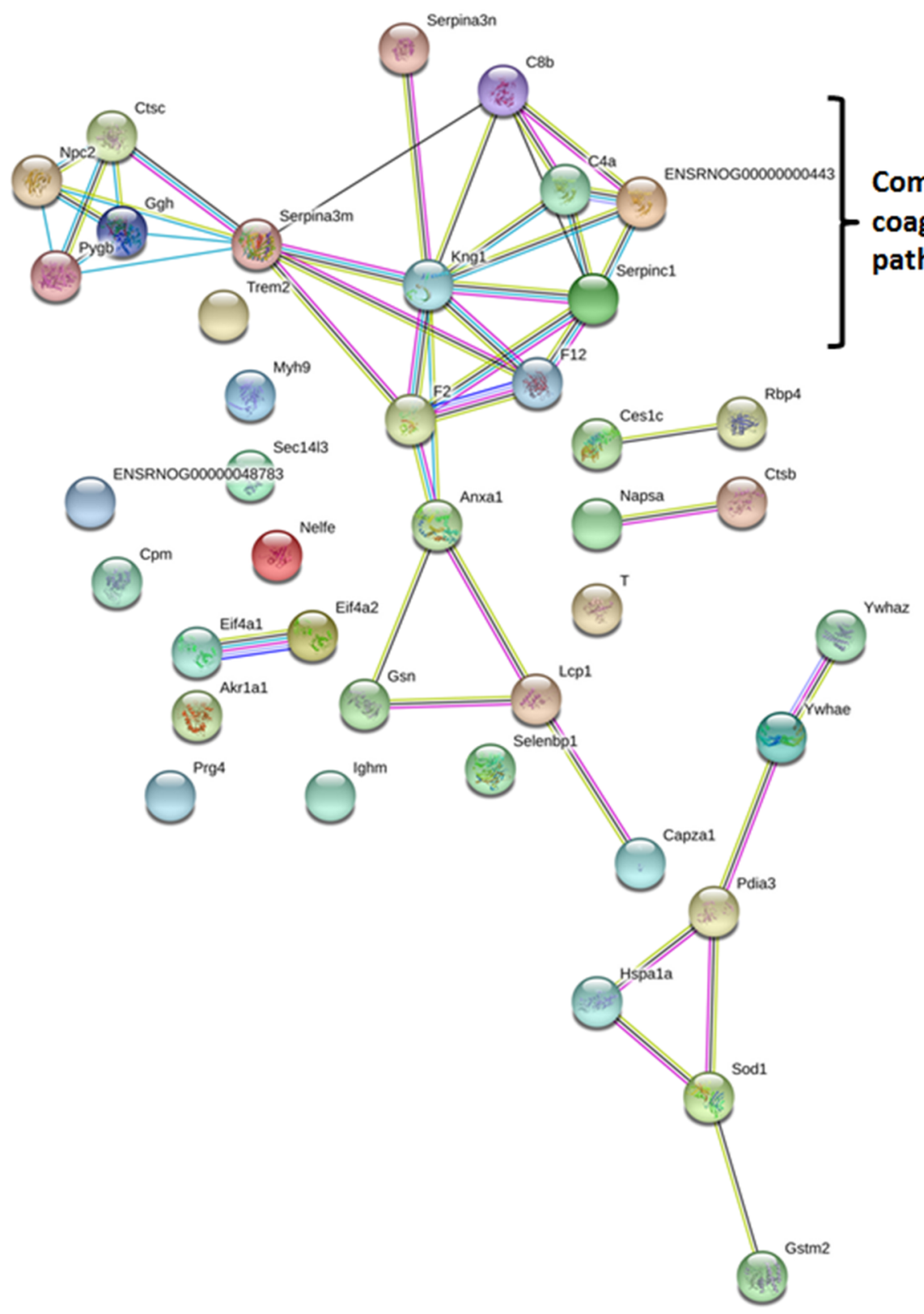


A

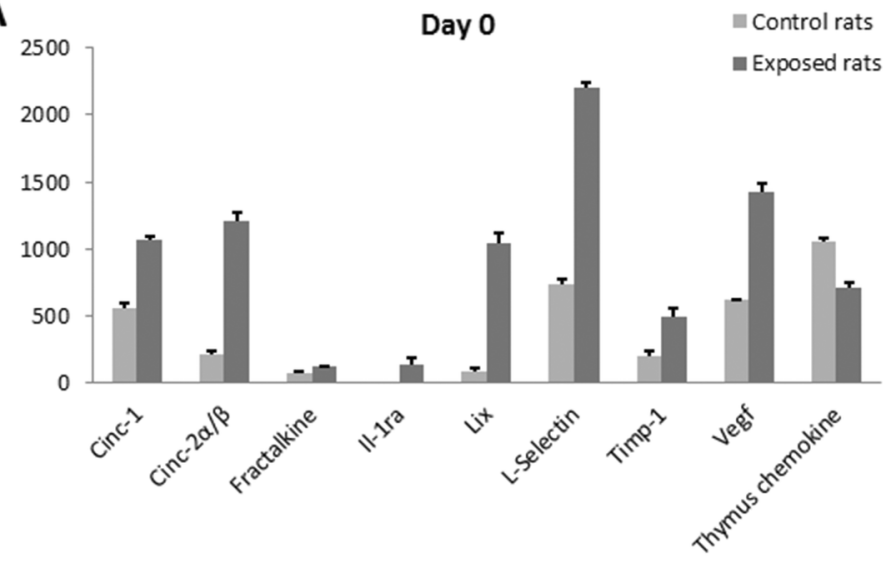

B

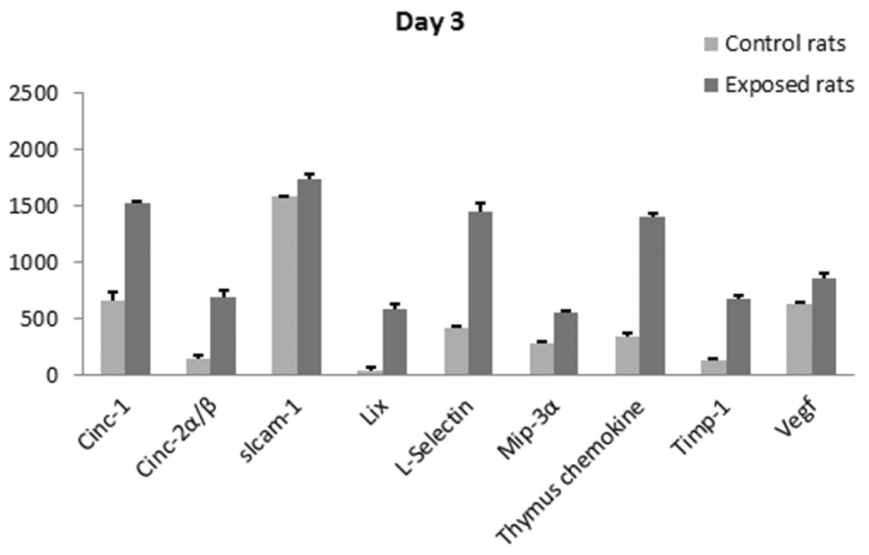

C

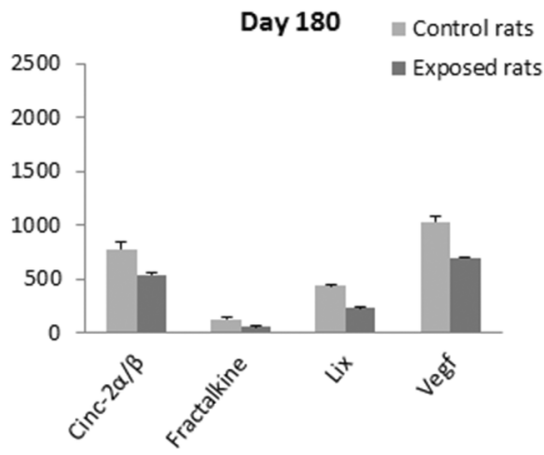




\section{Rat exposure to nanostructured aerosol of $\mathrm{TiO}_{2}$}

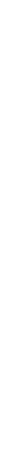

